\title{
Cross-cultural adaptation of the Developmental Coordination Disorder Questionnaire for brazilian children
}

\author{
Adaptação transcultural do Questionário de Transtorno do Desenvolvimento da \\ Coordenação para crianças brasileiras
}

Prado MSS', Magalhães LC'2, Wilson BN3

\begin{abstract}
Background: Developmental Coordination Disorder (DCD) is considered a major health problem among school-aged children worldwide. Although there are several instruments to identify children with DCD, none of them are translated into Portuguese and validated to be used in Brazil. Objectives: Considering that a parent questionnaire is a simple and effective method to screen children with DCD, this study describes the adaptation of the Developmental Coordination Disorder Questionnaire (DCDQ) and the pilot testing with Brazilian children. Methods: Translation of the DCDQ into Portuguese was conducted according to current guidelines for cross-cultural adaptation of instruments. The questionnaire was completed by parents of 15 children with motor coordination problems and parents of 30 children who were typically developing, matched for age. Five parents randomly selected from each group completed the questionnaire twice, to examine test-retest reliability. The parent's opinion regarding the quality of the questionnaire was recorded. Results: $91 \%$ of Brazilian parents reported no difficulty in completing the DCDQ. Examination of psychometric properties revealed that two items had limitations due to cultural differences. After item substitution, sensitivity increased from 0.66 to 0.73 and test-retest reliability from 0.95 to 0.97 . Internal consistency also increased from 0.91 to 0.92 . Conclusions: The translated instrument shows potential as a screening tool for children in Brazil and should be further examined. Research with a larger sample is needed in order to define cut-off scores and verify the instrument's validity and clinical utility. The use of the DCDQ will allow the comparison of epidemiological data from different countries.
\end{abstract}

Key words: Developmental coordination disorder; motor skills disorder; screening; cross-cultural translation; questionnaire; reproductibility of results.

\begin{abstract}
Resumo
Contextualização: O transtorno do desenvolvimento da coordenação (TDC) é considerado, em vários países, um grande problema de saúde para crianças. Apesar de existirem vários instrumentos para identificar o TDC, nenhum deles foi traduzido e validado para uso no Brasil. Objetivos: Considerando que um questionário de pais é um método simples e eficiente para fazer triagem de crianças com TDC, este estudo descreve a adaptação do Developmental Coordination Disorder Questionnaire (DCDQ) e o teste piloto com crianças brasileiras. Métodos: A tradução do DCDQ para o português foi feita de acordo com normas atuais para adaptação transcultural de instrumentos. O questionário foi respondido pelos pais de 15 crianças com problemas de coordenação motora e 30 crianças com desenvolvimento típico, emparelhadas por idade. Cinco pais de cada grupo, selecionados aleatoriamente, responderam ao questionário duas vezes para examinar a confiabilidade teste-reteste. A opinião dos pais sobre a qualidade do questionário foi registrada. Resultados: $91 \%$ dos pais brasileiros reportaram que não tiveram dificuldade para responder ao DCDQ. Exame das propriedades psicométricas revelou que dois itens apresentavam limitações devido a diferenças culturais. Após a substituição desses itens, a sensibilidade aumentou de 0,66 para 0,73, e a confiabilidade teste-reteste passou de 0,95 para 0,97. A consistência interna aumentou de 0,91 para 0,92. Conclusões: O questionário final mostrou bom potencial para ser examinado como instrumento de triagem no Brasil e deve ser melhor examinado. É necessário coletar mais dados para definir o ponto de corte e verificar a validade e a utilidade clínica. O uso do DCDQ vai contribuir para a comparação de dados epidemiológicos de diferentes países.
\end{abstract}

Palavras-chave: Transtorno do desenvolvimento da coordenação (TDC); transtornos das habilidades motoras; triagem; tradução transcultural; questionário; reprodutibilidade dos testes.

Received: 01/08/2008 - Revised: 15/12/2008 - Accepted: 22/01/2009

${ }^{1}$ Physiotherapie für Kinder, Gerlingen, Germany

2 Department of Occupational Therapy, Universidade Federal de Minas Gerais (UFMG), Belo Horizonte (MG), Brazil

${ }^{3}$ Decision Support Research Team, Alberta Health Services and University of Calgary, Calgary, Alberta, Canada

A summary of this study was presented as a poster at the 7th International Conference on DCD, in Melbourne, Australia, 2007.

Correspondence to: Monja Sales Prado, Weilimdorferstr.74/2, 70839 Gerlingen, Germany, e-mail: monja.s.prado@physio-kinder.de 


\section{Introduction $: \therefore$.}

With prevalence estimates of about $6 \%^{1}$, Developmental Coordination Disorder (DCD) is a condition that deserves special attention because of its impact on school and daily life ${ }^{2,3}$. Even though this condition is observed by many schoolteachers, as well as physical and occupational therapists, it is not an easy diagnosis to make due to multi-faceted diagnostic criteria and terminology problems. This condition has been known by several names (e.g., dyspraxia, minor neurological dysfunction, minimal brain damage, clumsiness) but, at a consensus meeting ${ }^{4}$, researchers from many countries decided to adopt the term DCD and its diagnostic criteria, as proposed by the DSM-IV 5 . The use of a worldwide uniform term facilitates communication between professionals from different disciplines and allows the comparison of research findings ${ }^{6}$.

There are many instruments to identify children with DCD, such as the Bruininks-Oseretsky Test of Motor Proficiency SecondEdition (BOT-2) ${ }^{7}$ and the Movement Assessment Battery for Children (MABC) $)^{8}$, but they depend on careful observation and scoring by trained professionals. Screening questionnaires, such as the MABC Checklist ${ }^{8}$, the Children's Self-Perceptions of Adequacy and Predilection for Physical Activity (CSAPPA) ${ }^{9}$ and the Developmental Coordination Disorder Questionnaire $(\mathrm{DCDQ})^{10}$ are easier to use with large groups of children.

The early identification of children with DCD enables intervention $^{11}$ and alleviates school and social problems ${ }^{12}$. However, identification is difficult in Brazil because all valid instruments were created in English speaking countries. A Brazilian standardized motor test could be developed, but the World Health Organization ${ }^{13}$ recommends the cross-cultural translation of existing instruments because this process is cheaper, faster and can facilitate collaboration, exchange of information and comparison between international populations of children.

An instrument that is useful in identifying children with DCD is the DCDQ, a parent questionnaire developed in Canada $^{10}$ and recently re-validated and extended for use with children aged 5 years to 15 years $^{14}$. The DCDQ is short, easy to use and low cost, and these are important characteristics to consider in the Brazilian health care and school systems. The items are scored on a five-point Likert scale, in which the parents compare the motor coordination of their child with other children of the same age. For example, parents are asked to respond to expressions such as "Throws a ball with control and precision" with scores ranging from "Not at all like your child" (score 1) to "Extremely like your child" (score 5). The total DCDQ score indicates "Probable DCD” or "Probably not DCD”, as well as performance within four factors (control during movement, fine motor/handwriting, gross motor and general coordination). It has demonstrated high internal consistency, with a Cronbach coefficient alpha of $0.88^{10}$. Concurrent validity was tested; the correlation between the DCDQ and the four composite scores of the BOTMP varied from 0.46 to 0.54 , and it was 0.59 with the MABC. The sensitivity of the questionnaire (the ability of the test to identify DCD when it is present) was $86.4 \%$ and the specificity (the ability to identify children without DCD) was $70.9 \%^{10}$.

Recently, Wilson et al. ${ }^{14}$ conducted a study using the 17-item DCDQ and additional items to re-validate its use with a population based sample. This resulted in the development of a revised, 15-item version (DCDQ'07) which had higher internal consistency; Cronbach's alpha was 0.94, and itemtotal correlations ranged from 0.93 to 0.94 . The sensitivity of the questionnaire was $85 \%$, and the specificity was $71 \%$. A revised scoring system, with cutoff points for three different age ranges, was also developed.

The DCDQ has been cross-culturally adapted to many countries, including the Netherlands ${ }^{15}$, Israel ${ }^{16}$ and Taiwan ${ }^{17}$. The translation of the DCDQ into Portuguese would represent a major advance in the process of identifying and supporting children with DCD in Brazil and would facilitate collaborative epidemiological studies to compare the motor skills of Brazilian children with other populations.

The aim of the present study was to: (a) translate the DCDQ into Portuguese, (b) begin to examine the psychometric qualities (test-retest reliability, internal consistency, sensibility, specificity and item adequacy) and the clinical utility of the adapted instrument with a small sample, and (c) identify possible limitations of the Brazilian adaptation and, if necessary, suggest the inclusion or exclusion of items to make it more clinically useful in further validation studies.

\section{Methods: :}

\section{Participants}

Forty-five children participated in this pilot study. Sample size was determined considering international guidelines for cross-cultural adaptation of questionnaires ${ }^{18}$, which suggests a sample of 30 to 40 participants to field test newly adapted instruments. The clinical group included 15 children with motor coordination problems, identified by experienced pediatric occupational therapists. Inclusion criteria included: (a) children receiving physical or occupational therapy for motor coordination problems, (b) ages 5 to 12 years, (c) attending regular schools, and (d) presenting no signs of a medical condition, specific neurological disease or mental disability. 
Each child with coordination problems was matched by age, within \pm 3 months, with a pair of children who were typically developing, one female and one male, for a total of 30 children. This control group was recruited from a private school in the city of Belo Horizonte. Inclusion criteria were: (a) no history of premature birth (before 37 weeks), (b) no cerebral palsy, autism, mental disability, hearing deficit, visual deficits, orthopedic problems, use of anticonvulsive drugs or any disease that lasted more than 3 months, and (c) no school problems or the need for any kind of motor therapy (i.e., physical, occupational or psychomotor therapy).

Children were recruited from private clinics and schools because parents of higher socioeconomic levels are more likely to have higher education, which was important to their ability to read and evaluate the items of the questionnaire. Further validation of the DCDQ-Brazil would need to include socioeconomic levels more representative of the country's population. This study was approved by the Ethics Committee of the Universidade Federal de Minas Gerais (COEP/UFMG no. 494/05).

\section{Instruments}

The 15-items of the DCDQ'07 were used, with six additional items used in the re-validation study in Canada, for a total of 21 items. The additional items were included as possible replacements for items which were not found to be psychometrically strong in this sample.

\section{Translation process}

With permission of the primary test developer, the translation was conducted according to guidelines developed by Beaton et al. ${ }^{18}$ for cross-cultural adaptation of instruments. This process involved the translation into the standard language and the adjustment of cultural words, idioms and, if necessary, complete transformation of some items in order to capture the same concept in the target culture ${ }^{19}$.

In the first stage, two qualified independent translators with different backgrounds (one with no knowledge about children with motor problems) translated the questionnaire from English into Portuguese (T1 and T2). The second stage consisted of compiling a synthesis of the $\mathrm{T} 1$ and $\mathrm{T} 2$ into a single Portuguese version of the DCDQ (T1/2). In stage three, two back-translations of the synthesis into English were done by two independent native English speakers, producing BT1 and BT2. In stage four, an expert committee composed of the two original translators and an occupational therapist developed the final version of the questionnaire, considering semantic, idiomatic, experimental and conceptual equivalence. Only minor adaptations were considered necessary: (a) to change sports which are not typical in Brazil, such as skiing and badminton, to similar activities, and (b) to alter the animal in the expression "bull in a china shop" to "elephant", to make it more understandable to parents. In order to evaluate the quality of the cultural adaptation, a few questions regarding item clarity and familiarity of the activities in the items were added at the end of the questionnaire.

Finally, as recommended by Beaton et al. ${ }^{18}$, the questionnaire was tested for clarity with five parents of children who were typically developing, ages 7 to 12 (2 females, 3 males). These parents reported that the questionnaire was easy to read and did not suggest any revisions. The primary developer of the DCDQ was informed at all stages of the translation process and approved the version of the questionnaire used in this study.

\section{Procedure}

A number of clinicians and private elementary school principals agreed to support the study. To obtain the clinical sample, experienced occupational therapists working in private clinics invited the parents of children with motor coordination problems to participate. If the parents agreed, they received further explanation of the procedures, a copy of the consent form, and the translated questionnaire. Only children whose parents returned the signed consent form were included in the study.

For the control group, parents were recruited by teachers in private schools, who sent the consent form and the translated questionnaire. The questionnaires and consent forms were returned to the teachers. Five parents from each group were randomly selected to complete the questionnaire twice, 14 days apart, to examine test-rest reliability.

\section{Data analysis}

Descriptive statistics were used to characterize the two groups according to age and gender. Considering the sample size, the ordinal characteristic of the DCDQ item scores, and the fact that most of the data did not comply with the normality criteria, all data analyses were conducted using nonparametric tests, with an alpha level of 0.05. Age differences between the groups were examined using the Mann-Whitney U-test. In order to examine differential responses related to gender or group membership (clinical and control), combinations of the Wilcoxon's test for two dependent groups were used to compare the total score and the scores for each item of the questionnaire. Then, to examine possible bias in the items, a series of item analyses were conducted. Internal consistency (Cronbach's alpha) and test-retest reliability using Intraclass 
Correlation Coefficient (ICC) were calculated for all 21 items. Considering that scores 4 and 5 (which indicate good motor skills) were the most frequent, chi-square analysis was used to compare the frequency of usage of these scores to identify items that did not present a differential response for each group. Further analyses were conducted in order to select the best combination of items to compose a final version of the questionnaire. Predictive validity (sensitivity, specificity, and positive and negative predictive values) was examined to identify the ability of different versions of the instrument to identify the diagnostic category of the child as 'clinical' or 'typically developing'. Finally, Kappa's coefficient was calculated to examine the degree of agreement between the child's classification according to each version of the questionnaire and the actual diagnosis.

\section{Results $: \therefore$.}

\section{Sample characteristics}

The clinical sample had 14 boys and one girl, with a mean age of 106.60 months ( $\mathrm{SD}=15.57)$. The control group had 15 boys and 15 girls, with a mean age of 109.70 months (SD=12.80). The Mann-Whitney test did not detect age differences between the control and clinical groups. Results of the Wilcoxon test indicated that boys and girls in the control group did not present significant differences in total scores $(Z=-0.974, p>0.05)$. There was a significant gender difference $(Z=-2.308, \mathrm{p}<0.05)$ for only one item (Runs with the same speed and form), with better performance for boys. Given that gender differences were noted in only one item, data for control boys and girls were combined for further analysis.

\section{Qualitative analysis of content}

Time to complete the questionnaire ranged from 3 to 25 minutes, with a mean of $10.44(\mathrm{SD}=4.95)$. The majority of the parents $(91 \%)$ understood all questions and reported that the DCDQ was easy to complete. Some parents indicated difficulties in understanding some items: (a) item 3 (Hits a ball or birdie) was indicated by four parents, and (b) item 13 (Elephant in a china shop) by eight parents. Overall, $91 \%$ of the parents reported that all activities of the DCDQ-Brazil were common in the daily routine of their children.

\section{Reliability of Item performance}

Table 1 reports the internal consistency and test-retest reliability of each of the 15 items. Eight were moderately correlated with the total score (0.45 to 0.59 ), six were strongly correlated ( 0.60 to 0.75 ) and one item was highly correlated at 0.80. The Cronbach alpha coefficient for the total score of these items was 0.92 , with alpha coefficient if items were deleted ranging from 0.90 to 0.92 .

The last column in Table 1 reports the ICC test-retest reliability for each item. Twelve items (80\%) had ICCs ranging from 0.81 to 1.00 . Two items presented moderate indices, 0.60 and 0.74 , and only item 13 (Elephant in a china shop) presented an ICC below an accepted level (0.44).

\section{Discriminative performance of items}

Table 2 presents a summary of the analyses measuring the ability of each item to discriminate between the clinical and the control groups. Wilcoxon's test indicated that the scores of children in the two groups were significantly different $(\mathrm{p}<0.5)$ on all items except for item 5 (Runs with the same speed and form) and item 13 (Elephant in a china shop).

Also shown in Table 2 are the percentages of scores of 4 and 5 for each item, in both groups, and the chi-square analyses of the differences between the groups. There were significant differences between the groups on all items, except two: item 3 (Hits a ball or birdie) and item 13 (Elephant in a china shop").

These analyses suggest that item 13 did not perform as expected in the present Brazilian sample; this item was also considered difficult to understand by some of the participating

Table 1. Reliability of items of the Research Edition of Translated DCDQ-Brazil.

\begin{tabular}{|c|c|c|c|}
\hline \multirow[b]{2}{*}{ DCDQ items ${ }^{a}$} & \multicolumn{2}{|c|}{ Internal consistency } & \multirow{2}{*}{$\begin{array}{c}\text { Test-retest } \\
\text { reliability } \\
\text { intraclass } \\
\text { correlation (ICC) }\end{array}$} \\
\hline & $\begin{array}{l}\text { Corrected } \\
\text { item-total } \\
\text { correlation }\end{array}$ & $\begin{array}{l}\text { Alpha } \\
\text { if item } \\
\text { deleted }\end{array}$ & \\
\hline 1. Throw ball & 0.75 & 0.91 & 0.93 \\
\hline 2. Catch ball & 0.55 & 0.91 & 0.88 \\
\hline 3. Hit ball & 0.58 & 0.91 & 0.83 \\
\hline 4. Jump over & 0.68 & 0.91 & 0.95 \\
\hline 5. Run \& stop & 0.45 & 0.92 & 0.74 \\
\hline 6. Plan activity & 0.59 & 0.91 & 0.83 \\
\hline 7. Writing speed & 0.58 & 0.91 & 0.92 \\
\hline 8. Writing legibly & 0.56 & 0.91 & 0.86 \\
\hline 9. Pencil pressure & 0.66 & 0.91 & 1.00 \\
\hline 10. Cutting & 0.61 & 0.91 & 0.81 \\
\hline 11. Likes sports & 0.80 & 0.90 & 0.97 \\
\hline 12. Learns new & 0.68 & 0.91 & 0.97 \\
\hline 13. Elephant in a shop & 0.56 & 0.91 & $0.44^{b}$ \\
\hline 14. Quick/ competent & 0.73 & 0.91 & 0.87 \\
\hline 15. No fatigue & 0.53 & 0.91 & 0.60 \\
\hline Total & - & 0.92 & 0.97 \\
\hline
\end{tabular}

altems are written in short form; 'Below expected values. 
Brazilian parents $(\mathrm{n}=8)$. Similarly, item 3 was considered difficult to understand by some parents $(n=4)$ because the activity was not typical in Brazilian children's play; item 3 also showed little difference in percentages of scores 4 and 5 between the clinical and control groups. A decision was made to drop both these items and substitute them for three of the additional items with strong psychometric properties, items 17, 19 and 21 (Table 3), provided by the Canadian study (B. Wilson, pers. comm., Aug 30 2006). Two different 15-item versions (A and B) were constructed; for both versions, item 13 was substituted with item 19 which is a typical activity for children. Item 3 was replaced with item 21 in Version A and item 17 in Version B (Table 3).

\section{Reliability of three research versions}

As shown in Table 4, Cronbach's alpha coefficient was 0.915 for the 15-item Canadian equivalent version, indicating high internal consistency. Versions A and B had very similar internal consistency (0.926 and 0.918). Test-retest reliability (ICCs) for the three versions ranged from 0.953 to 0.973 . In reviewing the reliability of these three versions, Version A appeared to have the strongest psychometric properties. With items 3 and 13 replaced, individual item test-retest reliability ranged from 0.60 to 1.00 .

\section{Predictive validity}

The ability of an instrument to accuratelyidentify a condition is calculated as sensitivity and specificity. Since versions A and $B$ were very similar in content to the Canadian equivalent, the cutoff scores from the DCDQ'07 for three different age ranges were used with all versions. Table 4 shows the values for predictive validity of the three versions of the questionnaire, which were calculated with data presented in Table 5. Kappa's values (Table 4) indicate fair to moderate agreement with the correct diagnostic classification.

Table 2. Discriminative performance of the items of the Research Edition of Translated DCDQ-Brazil.

\begin{tabular}{|c|c|c|c|c|c|c|}
\hline & \multicolumn{2}{|c|}{ Comparison of median scores } & \multicolumn{4}{|c|}{$\begin{array}{c}\text { Differences in percentage of scores } 4 \& 5 \\
\text { between clinical and typical samples }\end{array}$} \\
\hline & $\begin{array}{l}\text { Wilcox Z } \\
\text { score }^{2}\end{array}$ & $p$-value & $\begin{array}{l}\% \text { Clinical } \\
\text { Group }\end{array}$ & $\begin{array}{l}\text { \% Typical } \\
\text { Group }\end{array}$ & Chi- square & $p$-value \\
\hline 1. Throw ball & -2.850 & 0.002 & 20.0 & 70.0 & 10.045 & 0.004 \\
\hline 2. Catch ball & -2.365 & 0.016 & 26.7 & 63.3 & 5.380 & 0.029 \\
\hline 3. Hit ball & -1.958 & 0.048 & 20.0 & 36.6 & 1.296 & 0.321 \\
\hline 6. Plan activity & -2.865 & 0.002 & 46.7 & 93.3 & 12.600 & 0.001 \\
\hline 7. Writing speed & -3.075 & 0.000 & 26.7 & 86.7 & 16.200 & 0.000 \\
\hline 8. Writing legibly & -3.131 & 0.001 & 66.7 & 93.3 & 5.414 & 0.032 \\
\hline 9. Pencil pressure & -3.165 & 0.001 & 26.7 & 86.7 & 16.200 & 0.000 \\
\hline 10. Cutting & -2.811 & 0.003 & 46.7 & 83.3 & 6.544 & 0.016 \\
\hline 14. Quick/ competent & -3.164 & 0.001 & 20.0 & 83.3 & 17.064 & 0.000 \\
\hline 15. No fatigue & -3.107 & 0.001 & 46.7 & 86.7 & 8.182 & 0.010 \\
\hline
\end{tabular}

Comparison of median scores of DCD and control groups for each item. Highlighted items presented no significant difference in total score (Wilcoxon) or in the percentage of scores 4 and 5 in the two groups.

Table 3. Discriminative performance of the additional items of the Research Edition of Translated DCDQ-Brazil.

\begin{tabular}{|c|c|c|c|c|c|c|c|}
\hline & \multirow{2}{*}{$\begin{array}{c}\text { Test-retest } \\
\text { reliability } \\
\text { Intraclass } \\
\text { correlation (ICC) }\end{array}$} & \multicolumn{2}{|c|}{$\begin{array}{l}\text { Comparison of median } \\
\text { scores }\end{array}$} & \multicolumn{4}{|c|}{$\begin{array}{c}\text { Differences in percentage of scores } 4 \& 5 \text { between clinical anc } \\
\text { typical samples }\end{array}$} \\
\hline & & $\begin{array}{l}\text { Wilcox Z } \\
\text { score }^{2}\end{array}$ & $p$-value & $\begin{array}{l}\% \text { Clinical } \\
\text { group }\end{array}$ & $\begin{array}{l}\% \text { Typical } \\
\text { group }\end{array}$ & Chi- square & $p$-value \\
\hline 16. Runs & 0.849 & -2.899 & 0.002 & 73.3 & 93.3 & 3.462 & 0.157 \\
\hline 17. Bicycle & 0.992 & -2.191 & 0.029 & 53.3 & 80.0 & 3.462 & 0.086 \\
\hline 18. Competes & 0.922 & -1.680 & 0.097 & 60.0 & 86.7 & 4.114 & 0.062 \\
\hline 19. Cuts meat & 0.905 & -2.689 & 0.006 & 26.7 & 76.7 & 10.417 & 0.003 \\
\hline 20. Begin and finish & 0.571 & -2.419 & 0.014 & 46.7 & 90.0 & 10.167 & 0.003 \\
\hline 21. Team sports & 0.936 & -3.045 & 0.001 & 26.7 & 80.0 & 12.101 & 0.001 \\
\hline
\end{tabular}




\section{Discussion $: \because$.}

The purpose of this study was to conduct a cross-cultural adaptation of the DCDQ and to investigate the item adequacy and psychometric properties of the translated instrument. The questionnaire was easy to use and Brazilian parents completed it in about 10 minutes. There were almost no comprehension difficulties, and the parents reported that the majority of the items are observed in their children's daily activities. The terms "Hit a ball" and "Elephant in a china shop" seemed to be more difficult to judge for the Brazilian parents, which most likely reflected a cultural difference.

Internal consistency for all items was relatively high, which is in agreement with that obtained with Canadian children ${ }^{10}$. Only two items did not demonstrate stable test-retest reliability and most items showed significant differences in median scores between the clinical and control groups, except item 5 and item 13. When comparing the percentage of time that scores of 4 and 5 were given, all but two items ( 3 and 13) significantly discriminated between the control and the clinical groups.

The examination of the strength of individual items led to the development of two other test versions, with certain items excluded and substituted. Decisions about item substitution were based on the intention to maintain the characteristics of each factor of the original instrument. Only one item differed between versions A and B: "team sports" and "bicycle". These two versions were then compared with a Canadian equivalent version. The substitution of two items resulted in a slightly higher internal consistency. Similar findings were observed in a study in Taiwan ${ }^{17}$, where two items of the Chinese version of the DCDQ were eliminated to obtain better cultural adequacy, and this resulted in increased alpha values from 0.85 to 0.87 . Schoemaker et al. ${ }^{15}$ also observed constraints regarding item 11 and, when it was eliminated from the Dutch version, the alpha coefficient increased from 0.89 to 0.90 for children aged 8 and over, and from 0.87 to 0.88 for the 4 to 8 year age group.

In the present study, the exchange of two items was supported by the principle of using culturally relevant items in epidemiological studies. The deleted items represented an activity and an expression that were not common in Brazil and presented weaker psychometric properties. Substitution improved the reliability and predictive validity of the questionnaire. The final instrument was quite similar to the Canadian version, which facilitates comparable research findings across different countries.

Test-retest reliability was identical in both versions A and $\mathrm{B}$, and slightly higher than the version most similar to the Canadian DCDQ. Version A demonstrated the strongest sensitivity, specificity, positive and negative predictive value,
Table 4. Comparison of the three versions of the DCDQ-Brazil.

\begin{tabular}{lccc}
\hline & $\begin{array}{c}\text { Canadian } \\
\text { equivalent }\end{array}$ & Version A & Version B \\
\hline Mean score/SD & $58.64 \pm 11.67$ & $58.89 \pm 12.25$ & $59.20 \pm 11.88$ \\
\hline Test-retest reliability (ICC) & 0.953 & 0.973 & 0.973 \\
\hline Internal consistency & 0.915 & 0.926 & 0.918 \\
\hline Sensitivity & 0.666 & 0.733 & 0.666 \\
\hline Specificity & 0.83 & 0.866 & 0.866 \\
\hline Positive predictive value & 0.666 & 0.733 & 0.714 \\
\hline Negative predictive value & 0.833 & 0.866 & 0.836 \\
\hline Kappa value & $0.500^{\star *}$ & $0.600^{\star *}$ & $0.542^{*}$ \\
\hline
\end{tabular}

${ }^{*} \mathrm{p}<0.05 ;{ }^{* \star} \mathrm{p}=0.000$.

Table 5. Classification of the children according to total scores in the three versions of the DCDQ-Brazil.

\begin{tabular}{lllll}
\hline \multirow{2}{*}{ Age range } & Clinical group & \multicolumn{2}{c}{ Typical group } \\
& DCD & Not DCD & DCD & Not DCD \\
\hline
\end{tabular}

15-item Canadian Equivalent

\begin{tabular}{lrrrr}
\hline $5 y-7 y 11 m$ & 1 & 3 & 0 & 3 \\
\hline $8 y-9 y 11 m$ & 7 & 2 & 3 & 21 \\
\hline $10 y-14 y 11 m$ & 2 & 0 & 2 & 1 \\
\hline Total & 10 & 5 & 5 & 25 \\
\hline
\end{tabular}

15-item Version A

\begin{tabular}{lrrrr}
\hline $5 y-7 y 11 m$ & 1 & 3 & 0 & 3 \\
\hline $8 y-9 y 11 m$ & 8 & 1 & 2 & 22 \\
\hline $10 y-14 y 11 m$ & 2 & 0 & 2 & 1 \\
\hline Total & 11 & 4 & 4 & 26 \\
\hline
\end{tabular}

15-item Version B

\begin{tabular}{lrrrr}
\hline $5 y-7 y 11 m$ & 1 & 3 & 0 & 3 \\
\hline $8 y-9 y 11 m$ & 7 & 2 & 2 & 22 \\
\hline $10 y-14$ y $11 m$ & 2 & 0 & 2 & 1 \\
\hline Total & 10 & 5 & 4 & 26 \\
\hline
\end{tabular}

as well as better agreement concerning the diagnosis of DCD; therefore, Version A was chosen as the final translated version of the instrument. The psychometric properties of the new 15-item Brazilian questionnaire developed in this study are stronger than those reported for the DCDQ in the literature $^{15,20}$.

The values for sensitivity and specificity are below the recommended $80 \%$ and $90 \%$ respectively ${ }^{21}$. The sensitivity was lower than the specificity, which might be due to the informal diagnostic criteria used for the clinical sample, as some children may have had a motor delay in specific areas but not DCD. This may also have been due to the lack of confirmatory motor testing in both groups. In addition, high specificity is a common feature for instruments that are used to screen for a condition. Another problem detected was that, among the seven-yearold participants in the clinical group, only one of the four was classified as possible DCD in any of the three versions of the questionnaire, suggesting that the questionnaire may need further refinement for younger children. Further studies with larger samples of Brazilian children should examine this issue. 


\section{Conclusions : $:$.}

After adapting the DCDQ to the language and cultural characteristics of Brazilian children, we obtained a version of the instrument that was slightly different from the Canadian DCDQ'07, but apparently equivalent and with strong potential to screen for DCD among this population. Cultural adaptation included substitution of two items. The final version of the DCDQ-Brazil demonstrates satisfactory internal consistency and reliability.

Limitations of this study include the small sample size and the informal identification of children with DCD in the clinical sample. However, the main goal of this pilot study was to translate the instrument and verify item performance before undertaking major data collection, and this was accomplished. The final version of the DCDQ-Brazil is more in tune with the country's culture and seems to have good clinical utility.

Future research should include larger samples of typical Brazilian children, and individual item performance for the younger children should be further analyzed. Children with a formal diagnosis of DCD should be included to examine the accuracy of the DCDQ-Brazil in detecting this condition. All participants should receive formal motor testing in order to accurately examine concurrent validity and predictive ability. As the data indicates that this first version of the DCDQ-Brazil has acceptable psychometric characteristics for further validation and is easy to use, we suggest that the questionnaire will be useful not only for epidemiological studies in a diverse country like Brazil, but also for comparing data from different countries. More importantly, with the use of a reliable questionnaire, rehabilitation professionals will be able to contribute to the detection of a condition that is not well known in Brazil.

\section{Acknowledgements : :}

This study was supported by a grant from the Brazilian National Council of Research (Conselho Nacional de Pesquisa - CNPq). We appreciate the help of the translators, parents and therapists and school employees who participated in the study. Our special thanks to Lilian Diná Teodoro for her assistance in data collection.

\section{References $: \because$.}

1. American Psychiatric Association. DSM-IV-TR - Diagnostic and Statistical Manual of Mental Disorders. $4^{\mathrm{a}}$ Ed. Washington, DC: American Psychiatric Association; 2000.

2. Missiuna C, Moll S, King S, King G, Law M. A trajectory of troubles: parents impressions of the impact of developmental coordination disorder. Phys Occup Ther Pediatr. 2007;27(1):81-101.

3. Polatajko HJ, Cantin N. Developmental coordination disorder (Dyspraxia): an overview of the state of the art. Semin Pediatr Neurol. 2006;12(4):250-8.

4. Polatajko HJ, Fox M, Missiuna C. An international consensus on children with developmental coordination disorder. Can J Occup Ther. 1995;62:3-6.

5. American Psychiatric Association. Diagnostic and Statistical Manual of Mental Disorders. 4 $4^{\mathrm{a}} \mathrm{E}$. Washington DC: American Psychiatric Association; 1994.

6. Magalhães LC, Missiuna C, Wong S. Terminology used in research reports of developmental coordination disorder. Dev Med Child Neurol. 2006;48(1):937-41.

7. Bruninks RH, Bruininks BD. Bruininks-oseretsky test of motor proficiency, second edition (BOT-2). Bloomington, MN: Pearson; 2006.
8. Henderson SE, Sudgen DA. The movement assessment battery for children. Sidup: The Psychological Corporation; 1992.

9. Hay JA. Adequacy in and predilection for physical activity in children. Clinical Journal of Sports Medicine. 1992;2(3):192-201.

10. Wilson BN, Kaplan BJ, Crawford SG, Campbell A, Dewey D. Reliability and validity of a parent questionnaire on childhood motor skills. Am J Occup Ther. 2000;54(5):484-93.

11. Cantell MH, Smyth MM, Ahonen TP. Two distinct pathways for developmental coordination disorder: persistence and resolution. Hum Mov Sci. 2003;22(4-5):413-31.

12. Mandich $A D$, Polatajko $H J$, Rodger $S$. Rites of passage: understanding participation of children with developmental coordination disorder. Hum Mov Sci. 2003;22(4-5):583-95.

13. WHOQOL Group. The world health organization quality of life assessment (WHOQOL): position paper from the World Health Organization. Soc Sci Med. 1995;41(10):1403-9.

14. Wilson BN, Kaplan BJ, Crawford SG, Roberts G. Further validation and revision of the Developmental Coordination Disorder Questionnaire [texto na internet] Calgary: University of Calgary; acesso em 2007 jan 08; disponivel em: http://www.calgaryhealthregion.ca/dsrt/reportsandposters.htm. 
15. Schoemaker MM, Flapper B, Verheij NP, Wilson BN, Reinders-Messelink $\mathrm{HA}$, de Kloet A. Evaluation of the developmental coordination disorder questionnaire (DCDQ) as a screening instrument. Dev Med Child Neurol. 2006;48(8):668-73.

16. Traub RBI, Levi AW, Parush S. Validity and reliability of the developmental coordination disorder questionnaire for school-aged children in Israel. The Israel Journal of Occupational Therapy. 2005;14(4): E181.

17. Tseng MH, Fu CP, Wilson BN. Psychometric properties of a chinese version of the developmental coordination disorder questionnaire in community-based children. Submitted, October 2007.

18. Beaton DE, Bombardier C, Guillemin F, Feraz MB. Guidelines for process of cross-cultural adaptation of self-report measures. Spine. 2000;25(24):3186-91.

19. Guillemim F. Cross-cultural adaptation and validation of health status measures. Scand J Rheumatol. 1995;24(2):61-3.

20. Green D, Bishop T, Wilson BN, Crawford S, Hooper R, Kaplan BJ, Baird J. Is question-based screening part of the solution to waiting lists for children with developmental coordination disorder? British Journal of Occupational Therapy. 2005;68(1):2-10.

21. American Psychological Association. Standards for educational and psychological tests. Washington, DC: American Psychological Association; 1985 